\title{
Two fetuses in one family of arterial tortuosity syndrome: prenatal ultrasound diagnosis
}

\author{
Meiling Liang, Huaxuan Wen and Shengli Li* (D)
}

\begin{abstract}
Background: Arterial tortuosity syndrome (ATS) is a rare autosomal recessive connective tissue disorder chiefly characterized by elongated and tortuosity of the large and medium sized arteries and anomalies of the vascular elastic fibers. Here we reported cases of brother about ATS from the same family on the prenatal ultrasound diagnosis. Reports of this case are rare in antenatally and we draw the vessel simulated diagram to display visually.

Case presentation: Prenatal ultrasound scanning at 29 weeks of gestation of the first fetus showed obvious tortuous and elongated of the aortic arch, ductus arteriosus, left and right pulmonary arteries, carotid and subclavian arteries. Three months after delivery, Contrast-enhanced computed tomography images (CTA) were performed to clearly display vascular abnormalities consistent with prenatal diagnosis of ultrasound. Whole exome sequencing (WES) was performed eight months after birth, two heterozygous variants of SLC2A10 gene was detected in newborn and their father and mother, respectively. Prenatal ultrasound scan at 22 weeks of gestation of the second fetus showed similar cardiovascular imaging. After birth the siblings have facial characteristic features gradually as aging. No surgical intervention was performed in the siblings follow up 19 months.
\end{abstract}

Conclusions: The key points of prenatal ultrasound diagnosis of ATS are the elongation and tortuosity of the large and medium sized arteries. Genetic counseling is the process of providing individuals and families with information on the nature, inheritance, and implications of genetic disorders to help them make informed medical and personal decisions.

Keywords: Arterial tortuosity syndrome, Prenatal ultrasound diagnosis, Cutis laxa, Pulmonary artery sling

\section{Background}

Arterial tortuosity syndrome (ATS) is a rare autosomal recessive connective tissue disorder chiefly characterized by elongation and tortuosity of the large and medium sized arteries and anomalies of the vascular elastic fibers, and a propensity for arterial and aortic aneurysm formation with vascular dissection, caused by mutations in SLC2A10 [1, 2]. The first few years of life seem to be the

\footnotetext{
*Correspondence: Isl13530386700@126.com

Department of Ultrasound, Affiliated Shenzhen Maternity \& Child

Healthcare Hospital, Southern Medical University, Shenzhen 518028, China
}

most critical for potentially life-threatening events, particularly acute respiratory insufficiency and other complications related to pulmonary artery stenosis. Here we reported two cases of brothers about ATS from the same family on the prenatal ultrasound diagnosis.

\section{Case presentation}

A 29 weeks fetus suspected fetal heart abnormality was referred to our center for the detailed prenatal ultrasound scanning. Routine scanning demonstrated that the fetus was in good status without any extra-cardiac abnormalities. Echocardiography showed (Fig. 1) obviously tortuous and elongated of the great arteries include Arch, 
DA, LPA, RPA, LCA, RCA, LSA and RSA. An additional movie files show this in more detail. (See Additional files 1, 2 and 3: Video) Given the echocardiographic findings suggestive of a connective tissue disorder, genetic diagnosis was recommended but the gravida refuse all the invasive examination.

The newborn presented with respiratory distress after birth. Umbilical cord blood was performed chromosome microarray detection at the time of delivery in the first neonate, indicating no abnormalities of sex chromosome and autosomes with definite clinical significance. Postpartum CT diagnosis: pulmonary hypertension, left and right ventricular wall thickening, the aorta, PA and cervical artery were tortuous, and clinically suspected Marfan syndrome.

Three months after delivery in the first neonate, CTA was performed to clearly display vascular abnormalities. The MPA send out RPA and LPA, LPA distinctly tortuous and elongated through the front of the trachea. The aortic arch arises from the ascending aorta and pass backward to the left of the trachea and esophagus to join the descending aorta which lies farther than normal aortic arch system of man [3]. A left aortic arch which gives rise to the IA, LCA and LSA in that order, but they are all tortuous exactly (Fig. 2). Whole exome sequencing(WES)was performed 8 months after birth in the first baby, two heterozygous variants of SLC2A10 gene c.1057_1058delCT (p. L353Tfs*8) and c.912 T>G (p.C304W) were detected (Table 1) and sequencing data showed that the two mutations were inherited from the mother and father (both heterozygous). P. L353TFS * 8 is a rare code shift mutation predicts that protein synthesis may lead to premature termination of amino acids. P.c304w is a rare missense variation, and the variation region is an important part of this protein. Neither mutation has been reported in the associated clinical cases. So far, these two variants are relatively infrequent in our reference population gene database. In summary, according to the American Guidelines for classification of ACMG variants (PMID: 25,741,868), the two variants were classified as likely pathogenic variant and uncertain significance respectively, in combination with the clinical manifestation and pedigree analysis of the examinees.

The first baby followed up to 19 months, with normal growth and development and had been hospitalized for several times due to severe pneumonia and occasionally cough with dyspnea. Facial characteristic features gradually as aging, such as blepharophimosis or periorbital fullness, downslanted palpebral fissures, micrognathia, large ears, long face and cutis laxa. Echocardiography in child showed the Arch and PA were still tortuous. These extensive tortuous and elongated vessels would be difficult to handle in the operation according to the consultation of pediatric cardiac surgery experts. It has been reported that severe pulmonary stenosis usually requires surgery and/or transcatheter treatment, but aortic arch abnormality does not require intervention in most cases of ATS [4].

Prenatal ultrasound scanning at 22 weeks of gestation of the second fetus showed (Fig. 3) similar echocardiography with tortuous and elongated great arteries. An additional movie files show this in more detail. (See Additional file 4: Video) Parents who continue the pregnancy after prenatal consultation and are fully aware that both parents are carriers have a $25 \%$ chance of having the disease in their next child. Doctor suggested a genetic test for the second fetus, and the parents refused to do amniocentesis and also refused to do after birth.

\section{Discussion}

ATS was first described by Ertugul in 1967 [5] and Beuren et al. in 1968 [6]. ATS has no reliable estimate of prevalence. Some authors suggest that it may be more frequent than estimated [7]. However prenatal ultrasound diagnosis of ATS is very rare. Despite few reports of prenatal suspicion of ATS antenatally at 28,29,30 weeks but not have been confirmed after birth [8]. Recently has been reported a case confirmed homozygous for p.S81R pathogenic variant in the SCL2A gene diagnosis of ATS antenatally at 29 weeks and mother was the same variant, the baby appeared well after birth. 11 months of age revealed progressive and severe PA stenosis and taken up for an operation. At 18 months had obviously appearance like our sibling cases [9]. The literature affected the vessels about MPA and their branches and aorta, it's similar with our cases just elongated and tortuous there was no stenosis noted.

Due to the high suspicion of ATS in prenatal ultrasound and genetic confirmation, we summarized our experience and drew a simulated diagram to facilitate understanding and learning (Fig. 4). Both of our cases presented the same ultrasound appearance on prenatal ultrasound

\footnotetext{
(See figure on next page.)
}

Fig. 1 Prenatal ultrasound images and simulation of the first fetus at 29 weeks. A, C Tortuous of the AAO and aortic arch in the Left ventricular outflow tract plane and Color Doppler. E, G. DA, LPA and RPA were significantly longer and tortuous. The LPA originated from the MPA and passed in front of the trachea and esophagus in the three vessel sections and Color Doppler. I, J. The AAO, aortic arch, LPA and RSA were significantly longer and tortuous in the horizontal section of the HD flow imaging. B, D, F, H. The monograms of $\mathbf{A}, \mathbf{C}, \mathbf{E}, \mathbf{G}$ respectively. The measurement in detail as follows: AAO $0.51 \mathrm{~cm}$, Aortic Arch $0.49 \mathrm{~cm}$, MPA $0.61 \mathrm{~cm}$, RPA $0.26 \mathrm{~cm}$, LPA0.27, DA0.26 cm. AAO: ascending aorta; RSA: right subclavian artery; RV: right ventricle; LV: left ventricle; LA: left atrium; DAO: descending aorta; DA: ductus arteriosus; MPA: main pulmonary artery; SP: spine 


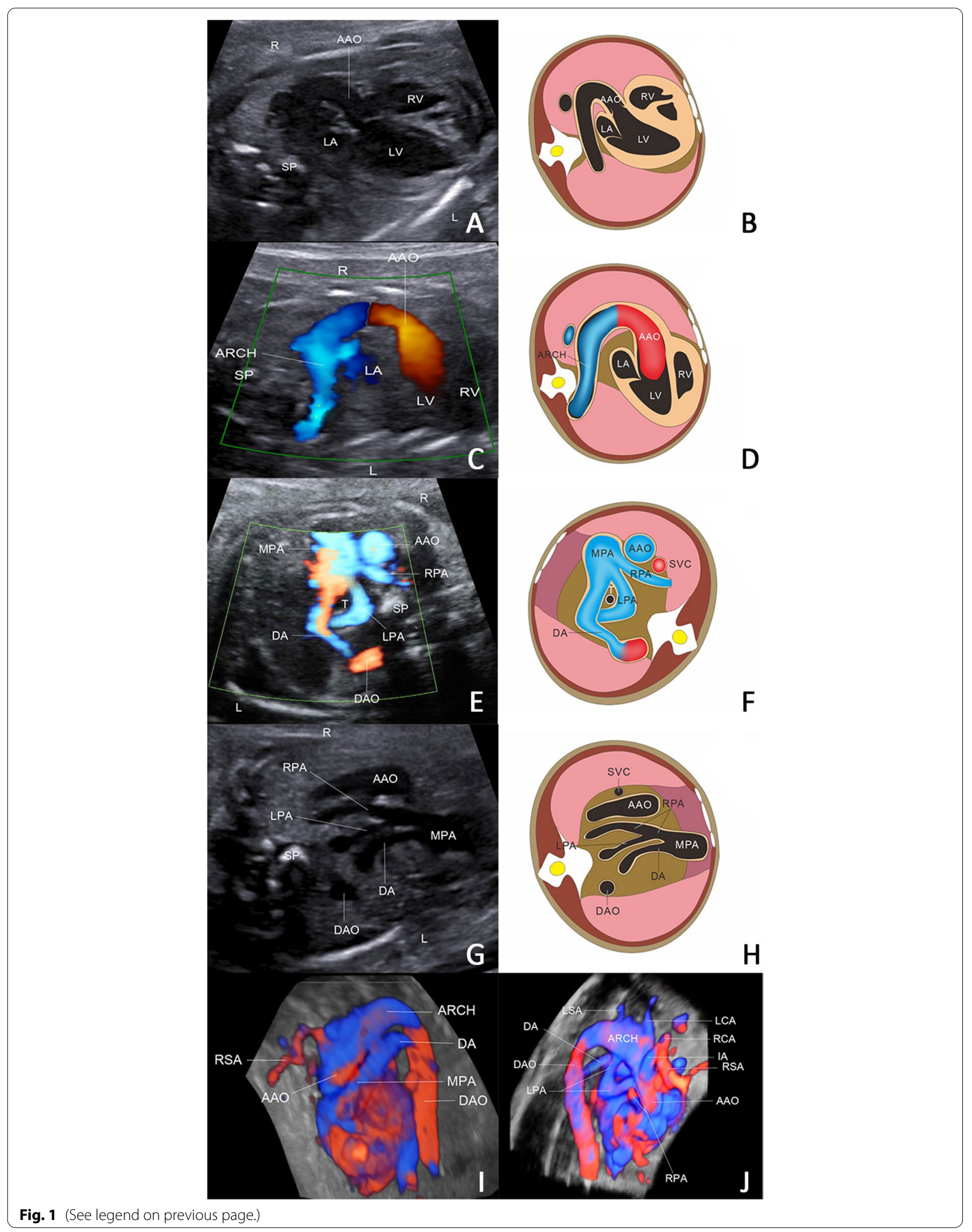




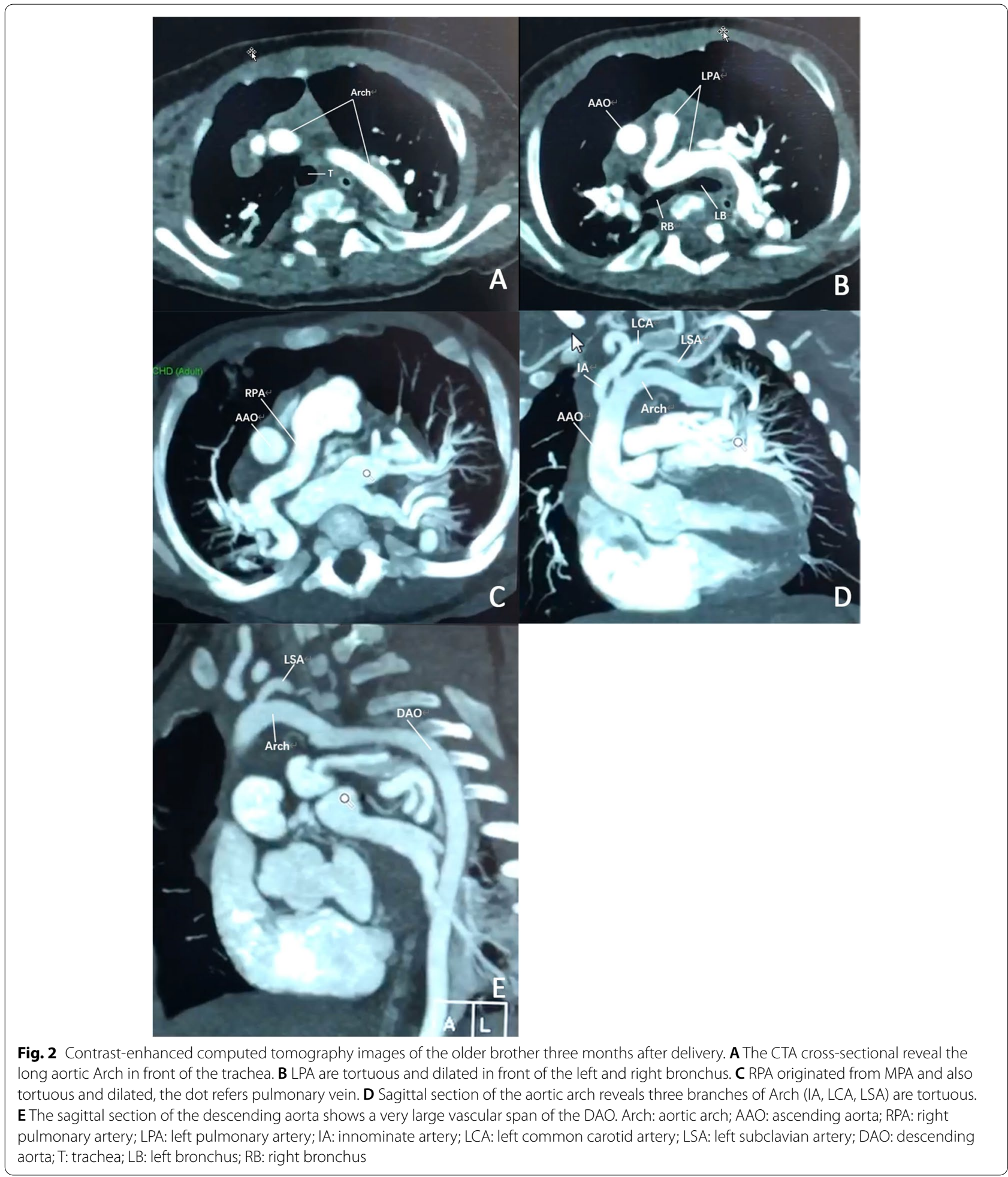

scanning. Fetal echocardiography revealed elongation and tortuosity of the large and medium sized arteries, postpartum CT showed the aorta is tortuous, dilated and elongated with large span, CTA cross-sectional section showed the tortuous and dilated LPA in front of the bifurcated left and right bronchi. The CTA longitudinal section about the first case showed the arch and three branches were abnormally zigzag. 
Table 1 Exon detection report

\begin{tabular}{|c|c|c|c|c|c|c|c|}
\hline Genes & Location of the HG19 & Transcript & $\begin{array}{l}\text { Changes of } \\
\text { Nucleotide and } \\
\text { amino acid }\end{array}$ & Frequency & ACMG variation & Related disease & Origin \\
\hline SLC2A10 & Chr20:45,354,728 & NM_030777 & $\begin{array}{l}\text { c.1057_1058delCT } \\
(\text { p.L353Tfs*8) }\end{array}$ & $<0.001$ & Likely pathogenic & $\begin{array}{l}\text { Arterial tortuosity } \\
\text { syndrome }\end{array}$ & Mother (Carriers) \\
\hline SLC2A10 & Chr20:45,354,587 & NM_030777 & c.912 T> G (p.C304W) & $<0.001$ & $\begin{array}{l}\text { Variant of uncer- } \\
\text { tain signifi- } \\
\text { cance }\end{array}$ & $\begin{array}{l}\text { Arterial tortuosity } \\
\text { syndrome }\end{array}$ & Father (Carriers) \\
\hline
\end{tabular}

Targeted exome sequencing that included 5,177 genes
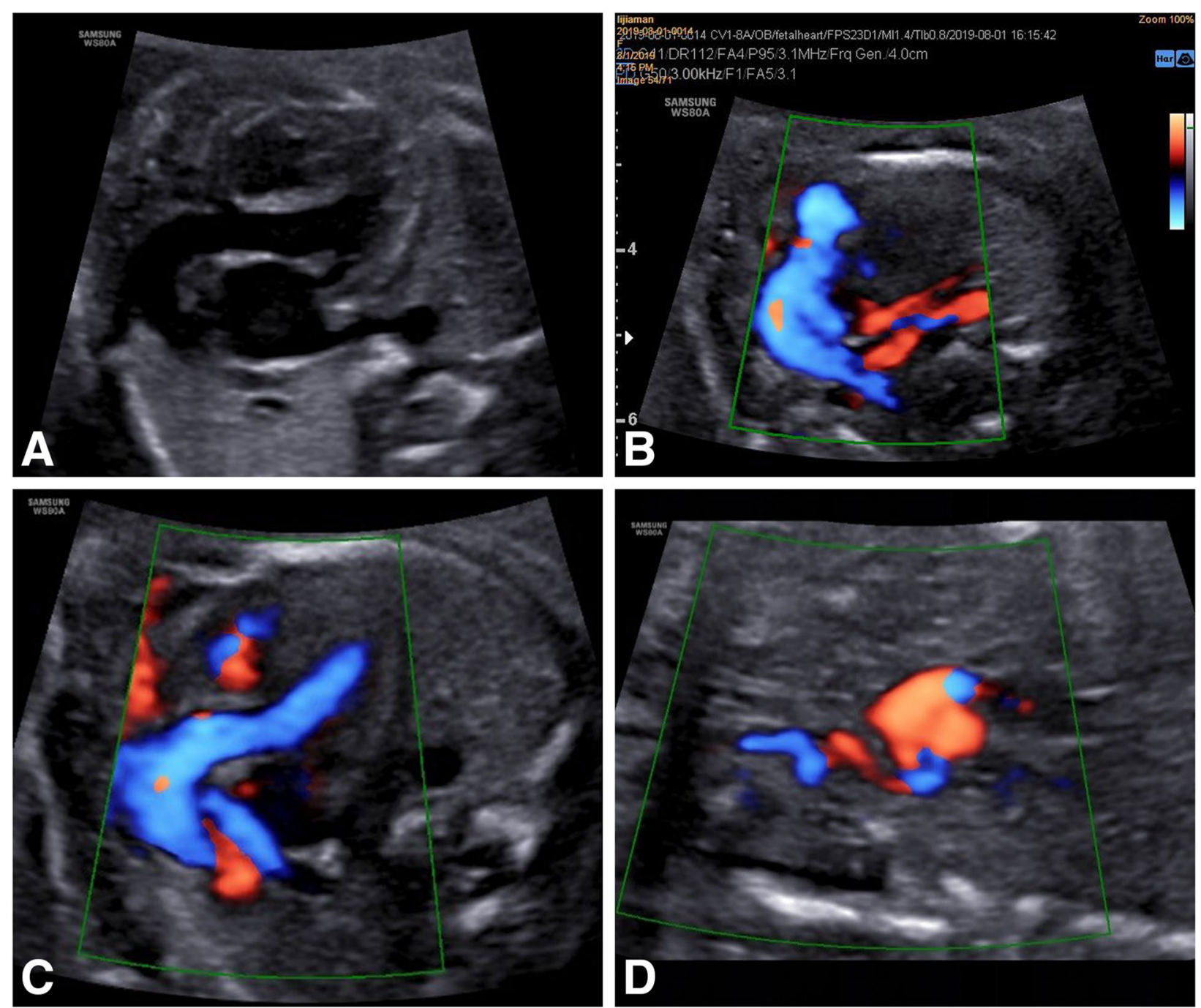

Fig. 3 The prenatal ultrasonic image of the second fetus at 22 weeks. A, C Showing the tortuous and elongated aorta that similar to the images of the first fetus. B RPA, LPA and DA are significantly elongated and tortuous. D RCA is tortuous originated from IA. The measurement in detail as follows: AAO $0.46 \mathrm{~cm}$, Aortic Arch $0.47 \mathrm{~cm}, \mathrm{MPA} 0.59 \mathrm{~cm}, \mathrm{RPA} 0.18 \mathrm{~cm}, \mathrm{LPA} 0.19 \mathrm{~cm}, \mathrm{DA} 0.19 \mathrm{~cm}, \mathrm{RCA} 0.19 \mathrm{~cm}$. AAO: ascending aorta; DA: ductus arteriosus; MPA: main pulmonary artery; RPA: right pulmonary artery; LPA: left pulmonary artery; RCA: right common carotid artery 


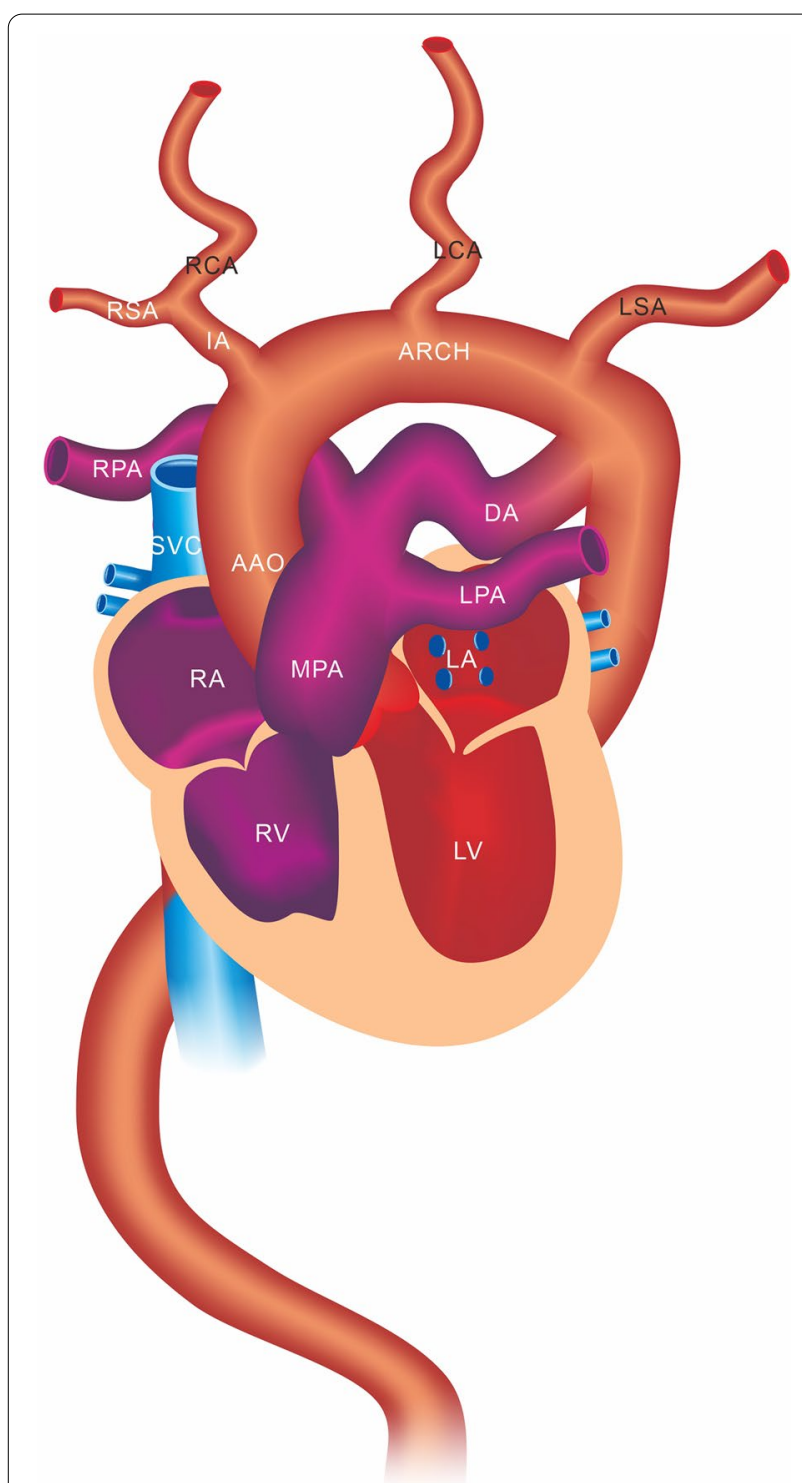

Fig. 4 The model diagrams of Arterial Tortuosity Syndrome reveals elongation and tortuosity of the large and medium sized arteries like MPA, LPA, RPA, AAO, Arch, IA, RCA, RSA, LCA, LSA and DAO. MPA: main pulmonary artery; RPA: right pulmonary artery; LPA: left pulmonary artery; AAO: ascending aorta; Arch: aortic arch; IA: innominate artery; RSA: right subclavian artery; RCA: right common carotid artery; LCA: left common carotid artery; LSA: left subclavian artery; DAO: descending aorta

Major clinical findings mainly divided into cardiovascular involvement, craniofacial involvement, skin and connective tissue disorder. In terms of cardiovascular disease, it could happen aneurysms [7, 10-12], pulmonary hypertension [11], large-vein dilation, valvular regurgitation and mitral valve prolapse $[13,14]$. The risk is also increased at any age for ischemic vascular events involving cerebrovascular circulation (resulting in non-hemorrhagic stroke) and the abdominal arteries (resulting in infarctions of abdominal organs). Characteristic features including blepharophimosis or periorbital fullness, downslanted palpebral fissures, convex nasal ridge, midface retrusion, micrognathia, large ears, long face, high palate, and dental crowding are often present and become more prominent with aging in the craniofacial involvement. The patients might be present loose skin folds and redundancy as seen in cutis laxa syndromes [7]. Other evidence of a generalized connective tissue disorder includes skeletal manifestations; inguinal and abdominal wall hernias; sliding hiatal or diaphragmatic hernia; hypotonia; myopia; and/or keratoconus [7]. Diaphragmatic hernia and sliding hiatal hernias are reported in up to $50 \%$ of affected individuals [15]. Although early reports mentioned $40 \%$ mortality before age four years [11], larger series of individuals with a molecularly confirmed diagnosis indicate a milder disease spectrum [7]. The earlier literature may also have been biased toward reporting the more severe end of the phenotypic spectrum. Abdulmohsen et al. published 7 patients at a mean follow up at 17.6 months remaining asymptomatic [16]. The diagnosis of ATS is established in a proband with generalized arterial tortuosity and biallelic (homozygous or compound heterozygous) pathogenic variants in SLC2A10.

ATS should be differentiated from EFEMP2-related cutis laxa, Loeys-Dietz syndrome [17, 18], Ehlers-Danlos syndrome, FBLN5-related cutis laxa, LTBP4-related cutis laxa and Occipital horn syndrome. And also differentiated from pulmonary artery sling antenatally, the crosssectional view at the level of three vessels which includes both PA branches is useful to detect and color and power doppler may be helpful as well. The difference is that the ATS is only PA tortuous and does not bypass the trachea, but the PA sling is the LPA originated from the RPA, originating initially to the right side of the trachea, and turning sharply to course between the trachea and esophagus prior to joining the left hilum [19]. In conclusion, the cases that both parents were carriers, each sib has a $25 \%$ chance of being affected, a $50 \%$ chance of being an asymptomatic carrier, and a $25 \%$ chance of being unaffected and not a carrier. The first case confirmed ATS and although genetic tests were not performed in the second case, ATS was highly suspected based on sonographic findings, facial features and the two cases from the same parents. Timely diagnostic work-up in patients with ATS is necessary to plan eventual intervention, and hopefully to prevent complications related to the abnormal vasculature [20]. Regular cardiovascular follow up with echocardiography, and MRI-angiography or CT scan with 3D reconstructions from head to pelvis starting at birth or at the time of diagnosis. Under stable conditions, 
echocardiography could be performed on a yearly basis and MRI angiography or CT scan at least every three years in older children and adults. Avoid the contact sports, competitive sports, isometric exercise, scuba diving, the tobacco and sun tanning [21]. Preconception counseling should include possible pregnancy-associated risks to the mother and medication-associated risks to the fetus. Genetic counseling is the process of providing individuals and families with information on the nature, inheritance, and implications of genetic disorders to help them make informed medical and personal decisions. It is appropriate to offer genetic counseling (including discussion of potential risks to offspring and reproductive options) to young adults who are affected, are carriers, or are at risk of being carriers.

\section{Conclusions}

Extra-cardiac abnormalities are difficult to detect, but the great vessel problems are easy to detect prenatally. In summarize, the key points of prenatal ultrasound diagnosis of ATS are the elongation and tortuosity of the large and medium sized arteries. There are great clinical implication of timely diagnostic work-up in patients with unusual appearance of great vessels of the fetal heart during routine morphology examination.

\begin{abstract}
Abbreviations
ATS: Arterial tortuosity syndrome; WES: Whole exome sequencing; CTA: Contrast-enhanced computed tomography images; AAO: Ascending aorta; RSA: Right subclavian artery; DAO: Descending aorta; DA: Ductus arteriosus; MPA: Main pulmonary artery; Arch: Aortic arch; RPA: Right pulmonary artery; LPA: Left pulmonary artery; IA: Innominate artery; LCA: Left common carotid artery; LSA: Left subclavian artery; T: Trachea; LB: Left bronchus; RB: Right bronchus.
\end{abstract}

\section{Supplementary Information}

The online version contains supplementary material available at https://doi. org/10.1186/s12884-021-03960-w.

Additional file 1. Fetus echocardiography showing the tortuous process of tracing the course and connecting about the great vessels include AAO, Arch, LPA, RPA, DA.

Additional file 2. Spatiotemporal image correlation (STIC) showing the correct vascular connection of the tortuous and elongated great vessels about the first fetus in the 22 weeks.

Additional file 3. Spatiotemporal image correlation (STIC) showing another view rotate the STIC images 180 degree to observe the backside about the first fetus in the 22 weeks.

Additional file 4. Sonogram showing the the tortuous process of tracing the course and connecting about the great vessels include AAO, Arch, LPA, RPA and DA about the second fetus in the 29 weeks.

\section{Acknowledgements}

We would like to thank Huaxuan Wen drawn the excellent simulated diagram, and thank Shengli Li guide to writing the manuscript.

\section{Authors' contributions}

$M L L, S L L$ and $H X W$ drafted the manuscript. SL $L$ and HXW performed the fetal echocardiography and the 3D post-analysis of the cardiac volumes. All authors read and approved the final manuscript.

\section{Funding}

The National Key Research and Development Program of China (2018YFC1002202); The National Nature Science Foundation of China (81771598); and Shenzhen Science and Technology project (JCYJ20170307091013214).

\section{Availability of data and materials}

The data supporting the conclusions of this article are included within the manuscript (and its additional files). The authors would like to share video data related to the current study, which could only be used for personal study.

\section{Declarations}

Ethics approval and consent to participate

Written informed consent was obtained from the patient for the publication of this case report.

\section{Consent for publication}

Informed written consent was obtained from the parents for publication of this report and any accompanying images.

\section{Competing interests}

The authors declare that there is no competing interest.

Received: 24 February 2021 Accepted: 11 June 2021

Published online: 12 August 2021

\section{References}

1. Callewaert B, De Paepe A, Coucke P. Arterial tortuosity syndrome. 2014 Nov 13 [Updated 2020 Nov 19]. In: Adam MP, Ardinger HH, Pagon RA, et al., editors. GeneReviews ${ }^{\circledR}$ [Internet]. Seattle: University of Washington, Seattle; 1993-2021. Available from: https://www.ncbi.nlm.nih.gov/books/ NBK253404/

2. Coucke PJ, Willaert A, Wessels MW, Callewaert B, Zoppi N, De Backer J, Fox JE, Mancini GMS, Kambouris M, Gardella R, Facchetti F, Willems PJ, Forsyth R, Dietz HC, Barlati S, Colombi M, Loeys B, Paepe AD. Mutations in the facilitative glucose transporter GLUT10 alter angiogenesis and cause arterial tortuosity syndrome. Nat Genet. 2006;38(4):452-7. https://doi.org/ $10.1038 /$ ng 1764.

3. Li S, Wen H, Liang M, Luo D, Qin Y, Liao Y, Ouyang S, Bi J, Tian X, Norwitz E, Luo G. Congenital abnormalities of the aortic arch: revisiting the 1964 Stewart classification. Cardiovasc Pathol. 2019;39:38-50. https://doi.org/ 10.1016/j.carpath.2018.11.004.

4. Ritelli M, Chiarelli N, Dordoni C, Reffo E, Venturini M, Quinzani S, Monica MD, Scarano G, Santoro G, Russo MG, Calzavara-Pinton P, Milanesi O, Colombi M. Arterial tortuosity syndrome: homozygosity for two novel and one recurrent SLC2A10 missense mutations in three families with severe cardiopulmonary complications in infancy and a literature review. BMC Med Genet. 2014;15:122. https://doi.org/10.1186/ s12881-014-0122-5.

5. Ertugrul A. Diffuse tortuosity and lengthening of the arteries. Circulation. 1967;36(3):400-7. https://doi.org/10.1161/01.cir.36.3.400.

6. Beuren AJ, Hort W, Kalbfleisch H, Müller H, Stoermer J. Dysplasia of the systemic and pulmonary arterial system with tortuosity and lengthening of the arteries. A new entity, diagnosed during life, and leading to coronary death in early childhood. Circulation. 1969;39(1):109-15. https:// doi.org/10.1161/01.cir.39.1.109.

7. Callewaert BL, Willaert A, Kerstjens-Frederikse WS, De Backer J, Devriendt K, Albrecht B, Ramos-Arroyo MA, Doco-Fenzy M, Hennekam RCM, Pyeritz RE, Krogmann ON, Fillessen-Kaesbach G, Wakeling EL, Nik-zainal S, Francannet C, Mauran P, Booth C, Barrow M, Dekens R, Loeys BL, Coucke PJ, Paepe AME. Arterial tortuosity syndrome: clinical and molecular findings 
in 12 newly identified families. Hum Mutat. 2008;29(1):150-8. https://doi. org/10.1002/humu.20623.

8. Al-Obaidly S, Kamal R, Al-Musafri F, et al. EP11.13: prenatal arterial tortuosity syndrome: a de facto late diagnosis. Ultrasound Obstet Gynecol. 2018:52:247.

9. Vijayashankar SS, Culham J, Moodley S. First antenatally confirmed case of arterial tortuosity syndrome[J]. Cardiol Young. 2020;30(11):1-3.

10. Pletcher BA, Fox JE, Boxer RA, Singh S, Blumenthal D, Cohen T, Brunson S, Tafreshi P, Kahn E. Four sibs with arterial tortuosity: description and review of the literature. Am J Med Genet. 1996;66(2):121-8. https://doi.org/10. 1002/(SICI)1096-8628(19961211)66:2\%3C121:AID-AJMG1\%3e3.0.CO;2-U.

11. Drera B, Guala A, Zoppi N, Gardella R, Franceschini P, Barlati S, Colombi M. Two novel SLC2A10/GLUT10 mutations in a patient with arterial tortuosity syndrome. Am J Med Genet A. 2007;143A(2):216-8. https://doi.org/10. 1002/ajmg.a.31514.

12. Allen VM, Horne SG, Penney LS, Rapchuk IL, Brock J-AK, Thompson DL, Stinson DA. Successful outcome in pregnancy with arterial tortuosity syndrome. Obstet Gynecol. 2009;114(2 Pt 2):494-8. https://doi.org/10. 1097/AOG.0b013e3181a99e52.

13. CastoriRitelliZoppiMolissoChiarelliZaccagnaGrammaticoColombi MMNLNFPM. Adult presentation of arterial tortuosity syndrome in a 51-yearold woman with a novel homozygous c.1411+1G>A mutation in the SLC2A10 gene. Am J Med Genet A. 2012;158A(5):1164-9. https://doi.org/ 10.1002/ajmg.a.35266.

14. LindsaySchepersBolarDoyleGalloFert-BoberKempersFishmanChenMyersBjedaOswaldEliasLevyAnderlidYangBongersTimmermansBravermanCanhamMortierBrunnerByersEykLaerDietzLoeys MEDNAJJEJMJEEKYLDGAFHPB-MMHEMHFJACNGRHGPHJVLVHCBL. Loss-of-function mutations in TGFB2 cause a syndromic presentation of thoracic aortic aneurysm. Nat Genet. 2012;44(8):922-7. https://doi.org/10.1038/ng.2349.

15. Zaidi SHE, Meyer S, Peltekova VD, Lindinger A, Teebi AS, Faiyaz-UI-Haque M. A novel non-sense mutation in the SLC2A10 gene of an arterial tortuosity syndrome patient of Kurdish origin. Eur J Pediatr. 2009;168(7):86770. https://doi.org/10.1007/s00431-008-0839-2.
16. Al-Khaldi A, Mohammed Y, Tamimi O, et al. Early outcomes of total pulmonary arterial reconstruction in patients with arterial tortuosity syndrome[J]. Ann Thorac Surg. 2011;92(2):698-704. https://doi.org/10. 1016/j.athoracsur.2011.03.068.

17. Loeys BL, Schwarze U, Holm T, Callewaert BL, Thomas GH, Pannu H, Backer JFD, Oswald GL, Symoens S, Manouvrier S, Roberts AE, Faravelli F, Greco MA, Pyeritz RE, Milewicz DM, Coucke PJ, Cameron DE, Braverman AC, Byers PH, Paepe AMD, Dietz HC. Aneurysm syndromes caused by mutations in the TGF- $\beta$ receptor. N Engl J Med. 2006;355(8):788-98. https://doi. org/10.1056/NEJMoa055695.

18. Van de Laar IMBH, Oldenburg RA, Pals G, Roos-Hesselink JW, de Graaf BM, Verhagen JMA, Hoedemaekers YM, Willemsen R, Severijene L-A, Venselaar $\mathrm{H}$, Vriend G, Pattynama PM, Collée M, Majoor-Krakauer D, Poldermans D, Frohn-Mulder IME, Micha D, Timmermans J, Hilhorst-Hofstee Y, Bierma-Zeinstra SM, Willems PJ, Kros JM, Oei EHG, Oostra BA, Wessels MW, Bertoli-Avella AM. Mutations in SMAD3 cause a syndromic form of aortic aneurysms and dissections with early-onset osteoarthritis. Nat Genet. 2011;43(2):121-6. https://doi.org/10.1038/ng.744.

19. Sezer S, Acar DK, Ekiz A, Kaya B, Bornaun H, Aslan H. Prenatal diagnosis of left pulmonary artery sling and review of literature. Echocardiography. 2019;36(5):1001-4. https://doi.org/10.1111/echo.14325.

20. Dodge-Khatami J, Simpson SA, Dodge-Khatami A. A severe form of arterial tortuosity syndrome presenting with significant airway obstruction in an infant[J]. World J Pediatr Congenit Heart Surg. 2020;11(2):238-40. https://doi.org/10.1177/2150135119829009.

21. Adam MP, Ardinger HH, Pagon RA, et al., editors. GeneReviews ${ }^{\circledR}$ [Internet] Seattle (WA): University of Washington, Seattle; 1993-2021. Available from: https://www.ncbi.nlm.nih.gov/books/NBK1116/

\section{Publisher's Note}

Springer Nature remains neutral with regard to jurisdictional claims in published maps and institutional affiliations.
Ready to submit your research? Choose BMC and benefit from:

- fast, convenient online submission

- thorough peer review by experienced researchers in your field

- rapid publication on acceptance

- support for research data, including large and complex data types

- gold Open Access which fosters wider collaboration and increased citations

- maximum visibility for your research: over $100 \mathrm{M}$ website views per year

At BMC, research is always in progress.

Learn more biomedcentral.com/submissions 